\title{
The role of 4D US in evaluation of fetal movements and facial expressions and their relationship with fetal neurobehaviour
}

\author{
Mihaela Grigore ${ }^{1,2}$, Dumitru Gafitanu¹, Demetra Socolov¹, Ana Maria Grigore ${ }^{3}$, \\ Georgiana Nemeti ${ }^{4}$, Romeo Micu $^{4}$
}

${ }^{1}$ Department of Obstetrics and Gynecology, "Grigore T. Popa" University of Medicine and Pharmacy, Iasi, ${ }^{2}$ Medis Medical Centre, Iasi, ${ }^{3}$ Student, "Grigore T. Popa"University of Medicine and Pharmacy Iasi, ${ }^{4}$ Department of Obstetrics and Gynecology, "Iuliu Hatieganu” University of Medicine and Pharmacy Cluj-Napoca, Romania

\begin{abstract}
The introduction of four-dimensional (4D) ultrasonography (US) allows the study of fetal movements and facial expressions in real time. The possibility of evaluating fetal movements has led to the study of fetal neurobehaviour, which has been for a long period of time a mystery for physicians. The study of fetal activity in utero could differentiate between normal and abnormal behavioural patterns, thus making possible the early recognition of fetal brain impairment. Facial expressions observed with 4D US represent a marker for neurobehaviour and at the same time could enhance fetal-maternal bonding. The present review represents an update of the literature on fetal movements, facial expressions, and their relationship with fetal neurobehaviour.
\end{abstract}

Keywords: fetal neurobehaviour; facial expressions; four-dimensional US; KANET test

\section{Introduction}

It is well accepted that the human brain represents the most complex and difficult organ to explore and the difficulties are even greater in the fetal and neonatal life. Despite this difficulty, it is important that children at risk of neurological impairment should be examined as early as possible (newborns and infants), for the assessment of their neurological development and early detection of central nervous system disorders [1].

Understanding the structure and function of the fetal nervous system has been both a desire and challenge for physicians over many centuries [2]. While brain structure studies started many years ago by post-abortion fetus ex-

Received 31.10.2017 Accepted 24.11.2017

Med Ultrason

2018, Vol. 20, No 1, 88-94

Corresponding author: Mihaela Grigore, MD, $\mathrm{PhD}$

University of Medicine and Pharmacy

"Grigore T.Popa" Iasi, Romania

Department of Obstetrics and Gynecology

Str.Universitatii 16, 700115 Iasi, Romania

Phone: +40744438024

E-mail: Mihaela.grigore@edr.ro amination, the study of fetal brain function remained for a long time a mystery for physicians. The latest development in the field of ultrasound (US) has made possible the study of fetal brain function early in fetal life. From the beginning, three-dimensional and four-dimensional (4D) ultrasonography (US) proved to be valuable tools for the diagnosis of several malformations of the fetus starting with the first trimester of pregnancy $[3,4]$. Further development of these technologies has permitted not only the study of the anatomy but also of the behaviour of the fetus. 4D US has the great advantage over 2D US because it enables simultaneous spatial imaging of the entire fetus and its movements $[5,6]$. It also initiated the development of new research directions, such as "fetal neurology", "fetal psychology" and "fetal neurobehaviour". Therefore, knowledge on fetal neurobehavior and neurodevelopment will be advanced through fetal behavioral research using this technique [7].

Cerebral palsy (CP) represents a group of disorders of movements and postural control caused by a defect or lesion of the brain and it is the most common chronic motor disability in childhood [8]. Identification of children with developmental disorder, such as CP, at early age is 
a difficult task for physicians [9]. Usually the diagnosis of CP is made six months postnatal when the child is already severely affected. Traditionally, it was accepted that brain damage appears during birth or early neonatal period. Actually this concept has changed and now is considered that antenatal factors are among the most important etiologic factors $[10,11]$. According to this theory many cases have the origin in prenatal period, therefore, constant attempts to diagnose neurological impairment in fetal life have been made in the last years [12].

Several studies on neonatal behavior showed that the assessment of behavior is a better predictor of neurodevelopmental disability than neurological examination $[1,2]$. An evolving challenge for the medical profession was and still remains to better define normal and abnormal fetal neurological function in utero, in order to better predict which fetuses are at risk for adverse neurological outcomes antenatal, regardless of intrapartum management $[1,13]$. Related to this purpose, fetal behavior is defined by fetal movement felt by the mother or observed by a more objective method, such as US [14].

The aim of this review is to present the current status of 4D US on fetal movement and fetal facial expressions as important markers for fetal brain development and function.

\section{Fetal movements}

Numerous studies have employed conventional twodimensional (2D) US or 4D US for the assessment of fetal behaviour as an indicator of fetal brain function and development [15-18]. Fetal movements were first assessed only by conventional 2D US on different periods of the pregnancy. While several studies of fetal movements were performed in the first trimester of pregnancy, others were focused on the second and third trimester $[19,20]$.

In 2005 Kurjak et al [13] started to analyse and to establish the standards of normal fetal behavioural patterns after 30 minutes of recording the fetus by 4D US. The authors showed that some types of movements are present through all trimesters while others are specific for different periods. For example, startle and stretch are specific for the first trimester, while some hand movement patterns or facial expressions, such as sucking and swallowing, are better observed in the second part of the pregnancy [13]. The main categories of fetal movements are synthetically described in table I.

Other studies have shown that the first trimester of pregnancy is characterized by a high frequency of fetal movement patterns, progressively increasing with gestational age. The only exception is represented by the startle movement, which has the same pattern during early gestation [21]. In the second trimester of pregnancy the incidence of body movements increases considerably alternating with longer periods of quiescence. The most frequent fetal movement involves the arms, whereas the least active is mouth movement. Among facial expressions, two types could be easily differentiated: smiling and scowling [14]. At the end of pregnancy, due to cerebral maturation process, the number of generalized movements decreases and, at the same time, an increase in facial movements (opening/closing of the jaw, swallowing and chewing) appear [14].

\section{KANET scoring system}

Kurjak et al developed the first scoring system for fetal neurobehavior based on prenatal assessment by $3 \mathrm{D} / 4 \mathrm{D}$

Table I. Categories of fetal movements according to Kurjak et al [13].

\begin{tabular}{|c|c|c|c|}
\hline & Type of movement & Movement speed & Gestational age (weeks) \\
\hline \multirow[t]{4}{*}{ Whole-body movements } & General movements & slow/rapid & $>8$ \\
\hline & Sideways bending & rapid & $7-8$ \\
\hline & Stretch & slow & $>9$ \\
\hline & Fetal rotation & rapid & $>10$ \\
\hline \multirow[t]{4}{*}{ Head movements } & Isolated head retroflexion & slow/fast, jerky & $>10$ \\
\hline & Isolated head anteflexion & slow & $>10$ \\
\hline & Isolated head rotation & slow & $>10$ \\
\hline & Jaw movements & slow/rapid & $>11$ \\
\hline \multirow[t]{5}{*}{ Limb movements } & Isolated arm/leg movement & slow/rapid & $>10$ \\
\hline & Startle & rapid & $>8$ \\
\hline & Clonic movements & very rapid & $>10$ \\
\hline & Twitches & rapid & $>9$ \\
\hline & Hand-head contact & slow & $>10$ \\
\hline \multirow[t]{4}{*}{ Functional movements } & Breathing - paradoxical breathing sequences & slow & $>10$ \\
\hline & Sucking and swallowing & slow/rapid & $>9$ \\
\hline & Hiccup & rapid & $>9$ \\
\hline & Yawning & slow & $>11$ \\
\hline
\end{tabular}


sonography - Kurjak antenatal neurodevelopmental test (KANET) [22]. The KANET scoring system combines parameters from other prenatal tests used previously (such as general movements assessment) and postnatal Amiel-Tison neurological assessment at term (ATNAT) [23]. KANET is a method that has been applied for the past 10 years and studies show that it is a strong diagnostic tool and can be introduced into everyday clinical practice [24].

The KANET test should be performed in the $3^{\text {rd }}$ trimester from $28^{\text {th }}$ to $38^{\text {th }}$ week of gestation for a period of 15-20 minutes. The fetus should be awake and if is sleeping, the exam should be postponed. Ten parameters are evaluated: assessment of cranial sutures, isolated head anteflexion, isolated hand, leg, hand to face and finger movements, isolated eye blinking, facial alterations, and mouth opening. These parameters were selected based on neurological development and on the theory of central pattern generators of general movements emergence [14,24]. The score has a three-point scale for several fetal movements (isolated head anteflexion, isolated hand, leg, hand to face, and finger movements) and a two-point scale for assessment of cranial sutures, isolated eye blinking, facial alterations and mouth opening. When the obtained score is abnormal or borderline the test should be repeated every two weeks till delivery [25]. KANET was used in several studies to compare fetal behavior and neurodevelopment of the fetus between low and high-risk pregnancies. All of the studies showed a score significantly higher in the low risk group compared to the high-risk group [2628]. Antsaklis et al studied the differences between the fetus of a normal pregnant women compared with pregnant women with diabetes under treatment with insulin. The results showed higher scores in the non-diabetic group, suggesting that there are differences in the fetal behaviour between diabetic and non-diabetic fetuses [29].

KANET score was also used to study the fetal behaviours in twin pregnancies and two types of activities were observed: spontaneous and reactive. Twins showed different behavioural pattern than singletons with less activity and a part of the overall motility was due to inter-twin contacts [30]. The different behavioural pattern of the twins does not translate into brain pathology but maybe into a different reaction to a different environment than singletons.

In cases of fetuses from high-risk pregnancies with KANET score modified or borderline, it is important to continue the follow-up after delivery. Postnatal evaluation should be done with ATNAT test and a brain US in the early neonatal period and every 2 weeks afterward till discharge. If the infants are affected by grade 3 and above intraventricular hemorrhage or if there is a suspicion of hypoxic ischemic brain damage, MRI should be recommended [25]. Children with CP should be reassessed at the age of 6 years.

In order to increase the reproducibility of the score, a standardization of the KANET test was recently proposed [25]. New modified KANET test should be used with eight instead of 10 parameters: facial and mouth movements were combined in one category and isolated hand movements together with hand to face movements were combined in one category [25].

\section{Facial expressions}

In daily life, our face presents a reflection of our reaction to different internal or external stimuli. Fetal response to different stimuli is observed by studying fetal face with 4D US. Facial expressions could represent the evidence of fetal brain development and may mirror the development of fetal consciousness [31] (fig 1).

The development of 4D US enabled to observe and study several fetal facial expressions such as: blinking, yawning, sucking, mouthing, tongue expulsion, scowling, and smiling from the early second trimester of pregnancy [16]. The fetal face expressions can reflect the fetal brain development and function during different stages of the fetus in utero [31].

The full range of facial movements can be studied by 4D US starting with 20 weeks of gestation because at this time both the facial and trigeminal nerves and facial muscles are formed [32]. They are easier to be studied after 24 weeks of gestation because of the deposition of adipose tissue starting this period [33]. The main facial expressions that can be observed are:

Fetal mouthing is considered to be the most frequent facial expression observed with 4D US [21,32,34-37].

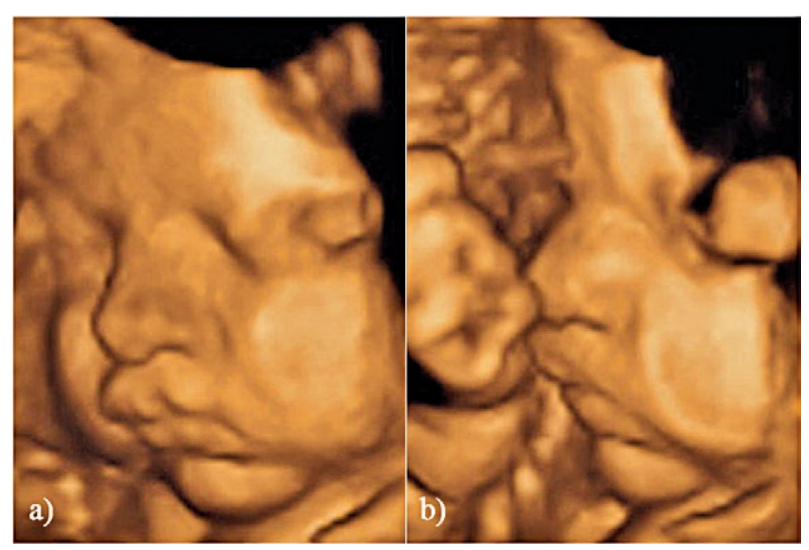

Fig 1. 4D US image of fetal face at 32 weeks of gestation: a) image of the nose, mouth and cheeks are clearly observed; b) the fetus is touching his nose with the hand 
Reissland et al described different patterns in fetal mouthing movements. They are represented by neutral mouth movements with a decreasing frequency with advancing gestation and lateralized mouth movements, which increase in frequency with advancing gestation [38] (fig 2a).

Blinking represents a reflex response and is an important parameter for fetal brain functional development, easily observed with 4D US [31]. It is regulated by the dopamine system and the increased rate of eye blinking along the pregnancy might be a parameter of the central dopamine system [39-42] (fig 2b). During pregnancy the rate increases until term when usually a slight decrease is observed [21,34-37].

Yawning - usually yawning during pregnancy experiences a change in frequency that indicates maturation of the brain [43] (fig 3). The frequency of yawning decreases after 28 weeks of gestation [44].

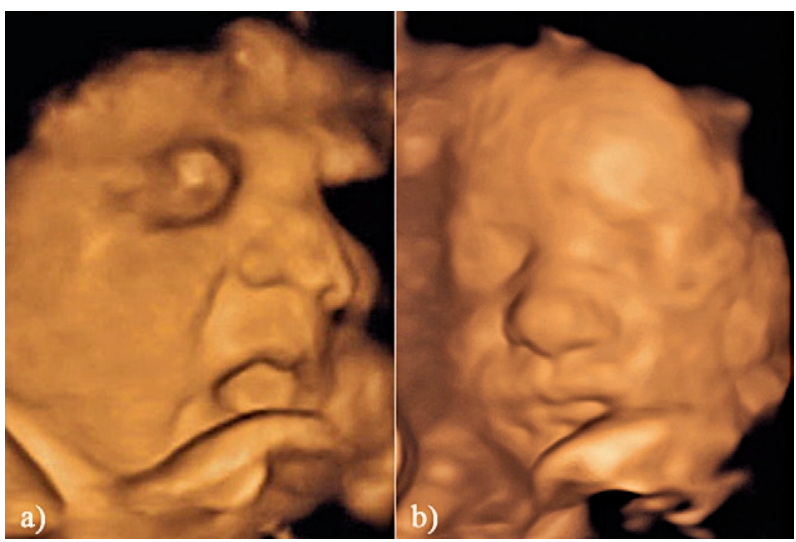

Fig 2. 4D US image of the fetus at 33 weeks of gestation: a) the mouthing movement is observed; $b$ ) the same fetus observed while blinking.
Suckling represents an essential process in the postnatal life. Several authors suggested that a fetus might prepare for feeding after birth in the second half of pregnancy [36]. The movement of fetal suckling is the indirect proof of normal brain development in utero (fig 4a).

Tongue expulsion outside the mouth requires both intact muscles with their innervations and higher brain centers with normal development in order to be performed. This facial movement could be another indirect sign of normal brain development, but there is a need for further research in order to establish the exact relationship between fetal tongue expulsion and the brain function [31].

Scowling - this facial expression could represent a sign of pain or stress of the fetus. The frequency of fetal scowling increases with advancing gestation. This observation suggests that fetal scowling is present while

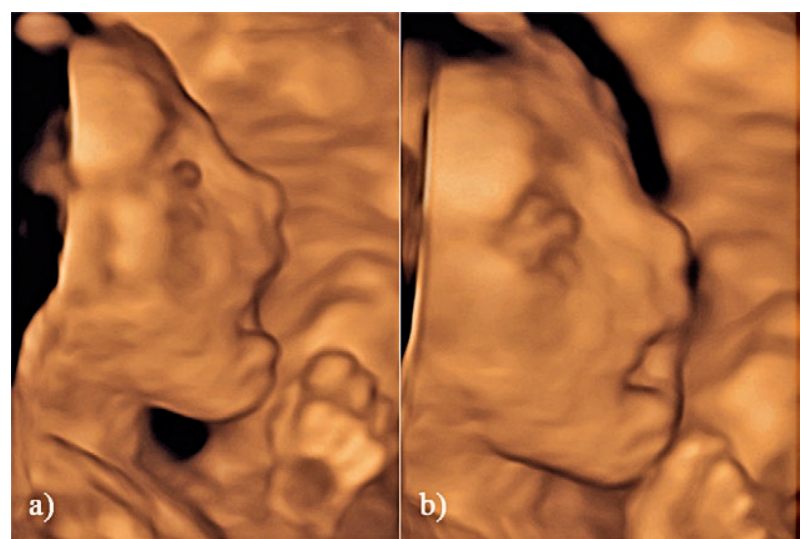

Fig 3. 4D US image a fetus at 29 weeks of gestation: a) the profile view of the fetus while yawning; b) the same fetus with the hand near the face while yawning.

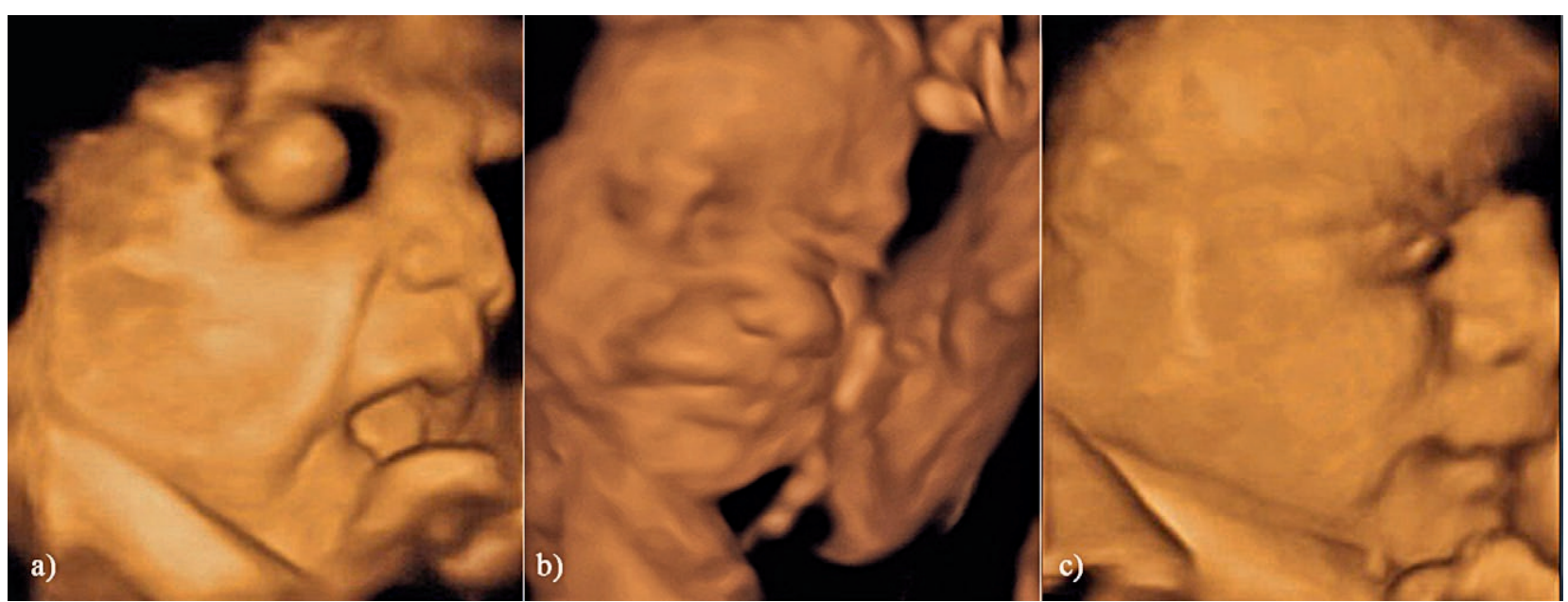

Fig 4. 4D US image a fetus at 29 weeks of gestation: a) the profile view of the fetus while yawning; b) the same fetus with the hand near the face while yawning. 
the fetal brain matures with advancing pregnancy [45] (fig $4 b$ ).

Smiling. There are different patterns of fetal smiling ranging from a simple facial expression to complex facial movements involving bilateral elevation of the mouth angles, or even to form laughter gestalt [33]. This facial expression is very impressive for the parents and could represent an indicator of fetal brain development [31] (fig 4c). At the same time it is considered that a fetal smile is spontaneous and does not result from social effects [46].

Several studies about fetal facial expressions have been published. Reissland et al compared facial expression of fetus from smokers versus non-smokers women. It appears that fetuses of mothers who smoked displayed higher rates of mouthing movements compared with those of nonsmokers [47]. Fetuses suffering from stress display higher frequencies of facial expressions compared with non-stressed fetuses [31].

Lopes-Teijnn et al evaluated the effects of music on fetus and observed a fetal response to intravaginal music in pregnant women between 14-39 weeks of gestation. The increased frequencies of tongue expulsion with advancing gestation observed in this study could indicate the developing of the auditory system with its neural pathways starting at 16 weeks of gestation [48].

Ferrari et al showed that fetuses seem to respond to specific maternal stimuli represented by a specific song with increased mouth opening. This response could represent a liaison that can contribute to harmony between mother and child in postnatal life [49]. Also when the pregnant women touched her abdomen the fetus showed mouthing movements according [50]. It was observed that fetuses in the third trimester showed an increased regulatory (yawning) response to the stimuli when compared with those in the second trimester [50].

Nakamura et al observed that fetuses in primiparas showed a higher rate of eye blinking than those in multiparas. Because, according to these authors primiparas had a higher state of relaxation than multiparas this study of facial expressions suggests that that relaxation might promote fetal brain maturation, especially the central dopamine system, which regulates blinking [51].

The observation of facial expressions is important not only for studying fetal neurobehaviour but also for fetal-maternal bonding. Evidence suggests that enhancing fetal-maternal bonding contributes to positive health behavior [52]. It was hypothesized that 3D US, by making possible to better visualize the baby, may have the potential benefit of increasing the bonding of mothers to their expected newborns and strengthening the support system for their families [53].

\section{Conclusions}

Human brain being the most complex structure of the human body represents a challenge for understanding and diagnosing its impairments from the early stages of life. The introduction of 4D US allowed the study of fetal movements and facial expressions in real time. 4D represents an important tool in the evaluation of both fetal brain development and function. The study of fetal activity in utero could differentiate between normal and abnormal behavioural patterns, and thus make possible the early recognition of fetal brain impairment. The fetal neurobehaviour evaluation by KANET score appears to be a feasible technique in monitoring fetuses of high-risk pregnancies.

\section{Conflict of interest: none}

\section{References}

1. Seme-Ciglenecki P. Predictive value of assessment of general movements for neurological development of high-risk preterm infants: comparative study. Croat Med J 2003;44:721-727.

2. Kurjak A, Carrera JM, Stanojevic M, et al. The role of 4D sonography in the neurological assessment of early human development. Ultrasound Rev Obstet Gynecol 2004;4:148159

3. Grigore M, Iliev G, Gafiteanu D, Cojocaru C. The fetal abdominal wall defects using 2D and 3D US. Pictorial essay. Med Ultrason 2012;14:341-347.

4. Grigore M, Iliev G. Diagnosis of sacrococcygeal teratoma using two and three-dimensional ultrasonography: two cases reported and a literature review. Med Ultrason 2014;16:274-277.

5. Kurjak A, Vecek N, Hafner T, Bozek T, Funduk-Kurjak B, Ujevic B. Prenatal diagnosis: what does four-dimensional ultrasound add? J Perinat Med 2002;30(1):57-62.

6. Kurjak A, Azumendi G, Vecek N, et al. Fetal hand movements and facial expression in normal pregnancy studied by four-dimensional sonography. J Perinat Med 2003;31:496508.

7. Hata T, Hanaoka U, AboEllail MAM, et al. Does parity have an effect on fetal behavior? A comparison between primi and multiparas. Donald School J Ultrasound Obstet Gynecol 2016;10:99-102.

8. Hadders-Algra M. General movements: A window for early identification of children at high risk for developmental disorders. J Pediatr 2004;145(2 Suppl):S12-S18.

9. Palmer FB. Strategies for the early diagnosis of cerebral palsy. J Pediatr 2004;145(2 Suppl):S8-S11.

10. Back SA, Riddle A, McClure MM. Maturation-dependent vulnerability of perinatal white matter in premature birth. Stroke 2007;38(2 Suppl):724-730. 
11. Back SA. Perinatal white matter injury: the changing spectrum of pathology and emerging insights into pathogenetic mechanisms. Ment Retard Dev Disabil Res Rev 2006;12:129-140.

12. Abo-Yaqoub S, Kurjak A, Mohammed AB, Shadad A, Abdel-Maaboud M.The role of 4D ultrasonography in prenatal assessment of fetal neurobehaviour and prediction of neurological outcome. J Matern Fetal Neonatal Med 2012;25:231-236.

13. Kurjak A, Stanojevic M, Andonotopo W, Scazzocchio-Duenas E, Azumendi G, Carrera JM. Fetal behavior assessed in all three trimesters of normal pregnancy by four-dimensional ultrasonography. Croat Med J 2005;46:772-780.

14. Kurjak A, Luetic AT. Fetal neurobehavior assessed by threedimensional/ four-dimensional sonography. Zdravniški Vestnik 2010;79:790-799.

15. Andonotopo W, Medic M, Salihagic-Kadic A, Milenkovic D, Maiz N, Scazzocchio E. The assessment of fetal behavior in early pregnancy: comparison between 2D and 4D sonographic scanning. J Perinat Med 2005;33:406-414.

16. Hata T, Kanenishi K, Hanaoka U, Marumo G. HDlive and 4D ultrasound in the assessment of fetal facial expressions. Donald School J Ultrasound Obstet Gynecol 2015;9:44-50.

17. Hata T. Current status of fetal neurodevelopmental assessment: Four-dimensional ultrasound study. J Obstet Gynecol Res 2016;42:1211-1221.

18. Kuno A, Akiyama M, Yamashiro C, Tanaka H, Yanagihara T, Hata T. Three-dimensional sonographic assessment of fetal behavior in the early second trimester of pregnancy. $\mathrm{J}$ Ultrasound Med 2001;20:1271-1275.

19. Shawker TH, Schuette WH, Whitehouse W, Rifka SM. Early fetal movement: a real-time ultrasound study. Obstet Gynecol 1980;55:194-198.

20. Roodenburg PJ, Wladimiroff JW, van Es A, Prechtl HF. Classification and quantitative aspects of fetal movements during the second half of normal pregnancy. Early Hum Dev 1991;25:19-35.

21. Yigiter AB, Kavak ZN. Normal standards of fetal behavior assessed by four-dimensional sonography. J Matern Fetal Neonatal Med 2006;19:707-721.

22. Kurjak A, Miskovic B, Stanojevic M, et al. New scoring system for fetal neurobehavior assessed by three and fourdimensional sonography. J Perinat Med 2008;36:73-81.

23. Amiel-Tison C. Neurological assessment of the neonate revisited: a personal view. Dev Med Child Neurol 1990;32:1109-1113

24. Kurjak A, Antsaklis P, Stanojevic M, et al. Multicentric studies of the fetal neurobehavior by KANET test. J Perinat Med 2017;45:717-727.

25. Stanojević M, Talic A, Miskovic B, et al. An attempt to standardize Kurjak's antenatal neurodevelopmental test: Osaka Consensus Statement. Donald School J Ultrasound Obstet Gynecol 2011;5:317-329.

26. Athanasiadis AP, Mikos T, Tambakoudis GP, et al. Neurodevelopmental fetal assessment using KANET scoring system in low and high risk pregnancies. J Matern Fetal Neonatal Med 2013;26:363-368.
27. Honemeyer U, Talic A, Therwat A, Paulose L, Patidar R. The clinical value of KANET in studying fetal neurobehavior in normal and at-risk pregnancies. J Perinat Med 2013;41:187-197.

28. Miskovic B, Vasilj O, Stanojevic M, Ivanković D, Kerner M, Tikvica A. The comparison of fetal behavior in high risk and normal pregnancies assessed by four dimensional ultrasound. J Matern Fetal Neonatal Med 2010;23:14611467.

29. Antsaklis P, Porovic S, Daskalakis G, Kurjak A. 4D assessment of fetal brain function in diabetic patients. J Perinat Med 2017;45:711-715.

30. Kurjak A, Talic A, Stanojevic M, et al. The study of fetal neurobehavior in twins in all three trimesters of pregnancy. J Matern Fetal Neonatal Med 2013;26:1186-1195.

31. AboEllail MAM, Kanenishi K, Mori N, Mohamed OAK, Hata T. 4D ultrasoundstudy of fetal facial expressions in the third trimester of pregnancy. J Matern Fetal Neonatal Med 2017 May 29:1-9. doi: 10.1080/14767058.2017.1330880.

32. Kurjak A, Azumendi G, Andonotopo W, Salihagic-Kadic A. Three- and four-dimensional ultrasonography for the structural and functional evaluation of the fetal face. Am J Obstet Gynecol 2007;196:16-28.

33. Reissland N, Francis B, Mason J, Lincoln K. Do facial expressions develop before birth? PLoS One 2011;6:e24081.

34. Yan F, Dai SY, Akther N, Kuno A, Yanagihara T, Hata T. Four-dimensional sonographic assessment of fetal facial expression early in the third trimester. Int J Gynecol Obstet 2006;94:108-113.

35. Kanenishi K, Hanaoka U, Noguchi J, Marumo G, Hata T. $4 \mathrm{D}$ ultrasound evaluation of fetal facial expressions during the latter stages of the second trimester. Int J Gynecol Obstet 2013;121:257-260.

36. Sato M, Kanenishi K, Hanaoka U, Noguchi J, Marumo G, Hata T. 4D ultrasound study of fetal facial expressions at 20-24 weeks of gestation. Int J Gynaecol Obstet 2014; $126: 275-279$.

37. Lebit DF, Vladareanu PD. The role of 4D Ultrasound in the assessment of fetal behaviour. Maedica (Buchar) 2011;6:120-127.

38. Reissland N, Francis B, Aydin E, Mason J, Exley K. Development of prenatal lateralization: evidence from fetal mouth movements. Physiol Behav 2014;131:160-163.

39. Bodfish JW, Powell SB, Golden RN, Lewis MH. Blink rate as an index of dopamine function in adults with mental retardation and repetitive behavior disorders. Am J Ment Retard 1995;99:335-344.

40. Colzato LS, van den Wildenberg WP, van Wouwe NC, Pannebakker MM, Hommel B. Dopamine and inhibitory action control: evidence from spontaneous eye blink rates. Exp Brain Res 2009;196:467-474.

41. DreisbachG, Muller J, Goschke T, et al. Dopamine and cognitive control: the influence of spontaneous eyeblink rate and dopamine gene polymorphism on perseveration and distractibility. Behav Neurosci 2005;119:483-490. 
42. Kleven MS, Koek W. Differential effects of direct and indirect dopamine agonists on eye blink rate in cynomolgus monkeys. J Pharmacol Exp Ther 1996;279:1211-1219.

43. Giganti F, Hayes MJ, Cioni G, Salzarulo P. Yawning frequency and distribution in preterm and near term infants assessed throughout 24-h recordings. Infant Behav Dev 2007;30:641-647.

44. Reissland N, Francis B, Manson J. Development of fetal yawn compared with non-yawn mouth openings from 24 36 weeks gestation. PLoS One 2012; 7:e50569.

45. Reissland N, Francis B, Mason J. Can healthy fetuses show facial expressions of "pain" or "distress"? PLoS One 2013;8:e65530.

46. Kawakami F, Yanaihara T. Smiles in the fetal period. Infant Behav Dev 2012;35:466-471.

47. Reissland N, Francis B, Kumarendran K, Mason J. U1trasound observations of subtle movements: a pilot study comparing foetuses of smoking and nonsmoking mothers. Acta Paediatr 2015;104:596-603.
48. Lopez-Teijon M, Garcia-Faura A, Prats-Galino A. Fetal facial expression in response to intravaginal music emission. Ultrasound 2015;23:216-223.

49. Ferrari GA, Nicolini Y, Demuru E, et al. Ultrasonographic investigation of human fetus responses to maternal communicative and non-communicative stimuli. Front Psychol 2016;7:354.

50. Marx V, Nagy E. Fetal behavioural responses to maternal voice and touch. PLoS One 2015;10:e0129118.

51. Nakamura Y, Takeishi Y, Ito N, Ito M, Atogami F, Yoshizawa T. Comfort with motherhood in late pregnancy facilitates maternal role attainment in early postpartum. Tohoku J Exp Med 2015;235:53-59.

52. Fletcher JC, Evans MI. Maternal bonding in early fetal ultrasound examinations. N Eng J Med 1983;308:392-393.

53. Ji EK, Pretorius DH, Newton R, et al. Effects of ultrasound on maternal-fetal bonding: a comparison of two- and three-dimensional imaging. Ultrasound Obstet Gynecol $2005 ; 25: 473-477$. 